ORIGINAL ARTICLE

\title{
Sertoli cell nodules in the undescended testis: a histochemical, immunohistochemical, and ultrastructural study of hyaline deposits
}

\author{
D Govender, Y Sing, R Chetty
}

J Clin Pathol 2004;57:802-806. doi: 10.1136/icp.2004.015982

See end of article for authors' affiliations ....................

Correspondence to: Professor D Govender, Division of Anatomical Pathology, Faculty of Health Sciences, University of Cape Town, Anzio Road, Observatory, Cape Town, 7925, South Africa; dgovende@chempath.uct. ac.za

Accepted for publication 23 February 2004
Aims: To document the morphology, immunohistochemical staining properties, and ultrastructural features of hyaline material in Sertoli cell nodules of undescended testis and contrast them with those of sex cord tumour with annular tubules (SCTAT), which is histologically similar. To highlight the need to distinguish these nodules from other Sertoli cell hyperplasias, such as intratubular Sertoli cell proliferations, which occur in specific clinical contexts.

Materials/methods: A retrospective study of 46 orchidectomy specimens from cryptorchid testes, 27 of which contained Sertoli cell nodules. Special histochemical stains, immunohistochemical stains for type IV collagen and fibronectin, and ultrastructural examination of the hyaline material were performed using tissue from paraffin wax embedded tissue blocks.

Results: The hyaline deposits in SCTAT and Sertoli cell nodules had similar staining patterns - periodic acid Schiff (PAS) and PAS-diastase positivity with variable staining of Martius scarlet blue and Masson trichrome. Type IV collagen immunoreactivity was seen in hyaline areas, although fibronectin was negative. Electron microscopy of hyaline areas confirmed a compact matrix identical to components of the basement membrane in the adjacent seminiferous tubules.

Conclusion: This study describes an unusual form of Sertoli cell proliferation in undescended testes, which must be distinguished from Sertoli cell tumours and other forms of proliferation. In addition, the hyaline material within Sertoli cell nodules in the cryptorchid testis is histochemically, immunohistochemically, and ultrastructurally consistent with both matrix and fibrous components of seminiferous tubule basement membranes. Increased production of basement membrane material, with subsequent invagination into tubules, is the most likely origin of this material.
$\mathrm{D}$ uring histological examination of cryptorchid testes, we found nodules of seminiferous tubules consisting of Sertoli cells only. These tubules were surrounded by a thickened basement membrane and many appeared to contain intratubular deposits of basement membrane-like material. The basement membrane-like hyaline material did have some resemblance to Call-Exner bodies, but the resemblance to sex cord tumour with annular tubules (SCTAT) was more striking. It has also been suggested that SCTAT shows Sertoli cell differentiation. Although Sertoli cell proliferation and hyperplasia has been reported in the cryptorchid testis, ${ }^{1}$ we describe an unusual form of Sertoli cell proliferation, which is morphologically similar to the recently reported intratubular Sertoli cell proliferations in infantile testes. ${ }^{2}$ Therefore, we undertook our study to compare this lesion with SCTAT morphologically, immunohistochemically, and ultrastructurally; to document the presence of these immature foci to prevent misinterpretation as neoplasia; and to distinguish them from intratubular Sertoli cell proliferations, which require more aggressive management.

\section{MATERIALS AND METHODS}

During the 14 year study period (1989-2002), 46 orchidectomy specimens of undescended testes were received. Formalin fixed, paraffin wax embedded tissue blocks were retrieved from the archives. The histochemical and immunohistochemical characteristics of the hyaline material in Sertoli cell nodules were compared with the basement membrane-like material in a case of SCTAT (courtesy of Professor A Tiltman, Johannesburg, South Africa).
Special stains, including periodic acid Schiff (PAS), PASdiastase, Martius scarlet blue, Masson trichrome, elastic van Giesson, and immunohistochemistry were performed in all cases. For immunohistochemistry, $3 \mu \mathrm{m}$ thick sections were cut and mounted on poly-L-lysine coated glass slides ( Sigma Diagnostics, St Louis, Missouri, USA). The sections were then heat fixed for 10 minutes at $60^{\circ} \mathrm{C}$ and dewaxed. Antigen retrieval was achieved by microwave pretreatment (H2500 microwave processor; Energy Beam Sciences Inc, Agawam, Massachusetts, USA) in a $0.01 \mathrm{M}$ trisodium citrate (bihydrate) solution ( $\mathrm{pH} 6.0$ ) for 10 minutes at $85^{\circ} \mathrm{C}$.

Endogenous peroxidase activity was blocked by incubating sections in an aqueous solution of 3\% hydrogen peroxide for 10 minutes. Sections were stained with monoclonal anticollagen type IV (clone CIV 22, prediluted; Dako, Carpinteria, California, USA) and polyclonal anti-fibronectin (1/800 dilution; Dako A/S, Glostrup, Denmark) using the peroxidase labelled streptavidin-biotin kit (Dako). The reaction was visualised using 3,3' diaminobenzidine (liquid DAB; Dako) as a chromogen. Sections were counterstained with haematoxylin. Positive controls and negative controls, in which the primary antibody was omitted, were also run simultaneously.

Ultrastructural examination was performed on tissue retrieved from paraffin wax embedded tissue blocks. After dewaxing, tissue was fixed in 3\% glutaraldehyde, postfixed in buffered osmium tetroxide, and embedded in epoxy resin (Araldite). Sections ( $1 \mu \mathrm{m}$ thick) were stained with toluidine blue. Ultrathin sections for electron microscopy were stained

Abbreviations: PAS, periodic acid Schiff; SCTAT, sex cord tumour with annular tubules 
with potassium permanganate, uranyl acetate, and lead citrate.

\section{RESULTS}

Of the 46 orchidectomy specimens, 27 contained Sertoli cell nodules. The ages of these 27 patients ranged from 12 to 35 years (mean, 22.5; median, 22). None of the patients had endocrine abnormalities or syndromic features.

Histological examination showed varying degrees of atrophy of the seminiferous tubules, with associated thickening of the basement membranes and interstitial fibrosis. Adenomatous hyperplasia of the rete testis was a consistent finding in all cases. In addition, each testis had multiple Sertoli cell nodules, which consisted of tubule-like structures composed exclusively of Sertoli cells (fig 1). The profiles of the tubule-like structures varied from round to oval to hour glass in shape. Some profiles had the appearance of lumina filled with round or oval hyaline deposits. However, other sections confirmed that these hyaline cores were in fact continuous with the surrounding basement membrane (fig 2). There were also areas composed of ring shaped tubules surrounding hyaline material similar to that seen in SCTAT (fig 2). The Sertoli cells had round to elongated nuclei with evenly distributed chromatin, regular outlines, and small but distinct eosinophilic nucleoli. There were areas of nuclear pseudostratification. The cytoplasm, mainly disposed apically (supranuclear), was clear to pale eosinophilic. Mitotic figures were not seen.

By comparison, SCTAT was characterised by circumscribed columnar epithelial nests composed of ring shaped tubules encircling hyaline basement membrane-like material. These were in two patterns: first, large islands of cells encircling multiple hyaline deposits, and second, single tubules encircling a single hyaline deposit. This last pattern was similar to that seen in Sertoli cell nodules in the undescended testis.

The hyaline deposits in Sertoli cell nodules and SCTAT showed similar staining characteristics. The hyaline deposits stained intensely with PAS and PAS-diastase, but showed variable staining with the Martius scarlet blue and Masson trichrome stains. On Masson trichrome stain, the deposits were green with peripheral fucsinophilia closer to the Sertoli cells. They also showed immunoreactivity for collagen type IV (fig 3) but did not stain with anti-fibronectin (fig 4). The surrounding interstitium stained with anti-fibronectin (fig 4). Staining for type IV collagen was linear and present in the

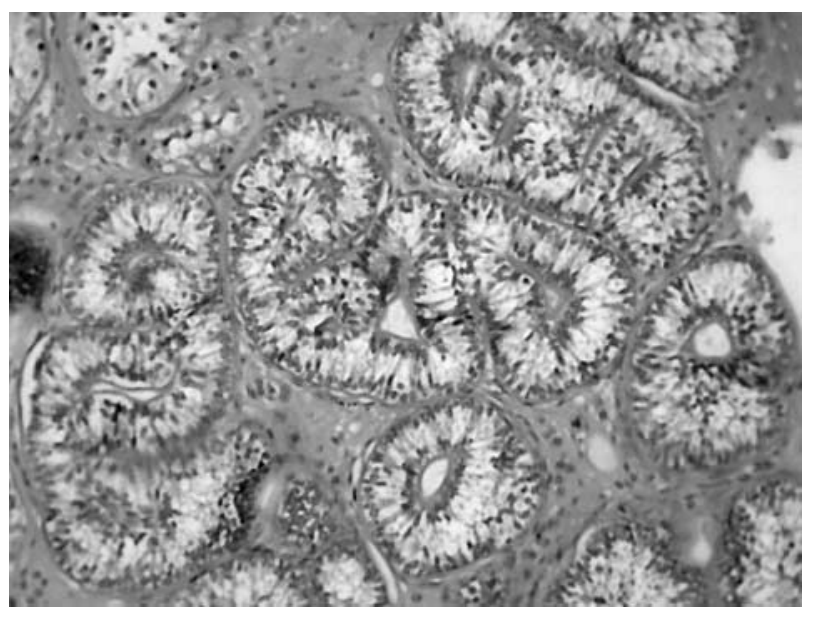

Figure 1 Sertoli cell nodule consisting of tubule-like structures composed exclusively of Sertoli cells with hyaline cores (haematoxylin and eosin stain).

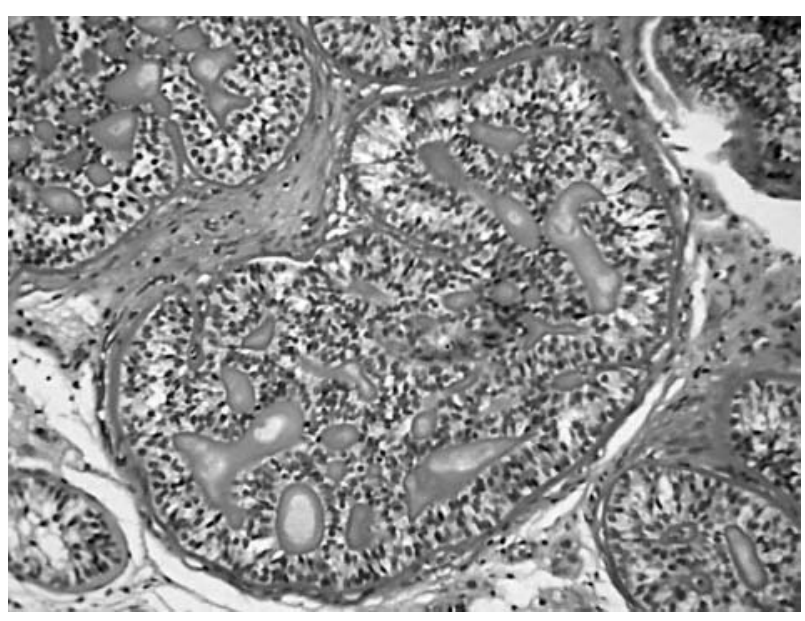

Figure 2 The Sertoli cells had round to elongated nuclei with evenly distributed chromatin and regular outlines. There were areas of nuclear pseudostratification. The cytoplasm was clear to pale eosinophilic. The hyaline cores were continuous with the surrounding basement membrane (haematoxylin and eosin stain).

basement membrane close to the basal regions of the Sertoli cells (fig 3). In addition, the rounded hyaline deposits also showed immunoreactivity for collagen type IV (fig 3).

Electron microscopy showed a compact multilamellar matrix corresponding to the hyaline material seen on light microscopy (figs 5, 6). This was identical to components seen in the basement membranes of the adjacent seminiferous tubules.

\section{DISCUSSION}

The lamina propria of the human seminiferous tubules consists of five to seven incomplete layers of flattened cells separated by laminae of extracellular connective tissue components consisting of connective tissue fibres and amorphous ground substance. ${ }^{3}$ The inner three to four cellular layers consist of myofibroblasts (myoid cells) and the outer one to two layers of fibroblasts. The seminiferous tubular epithelium is separated from the rest of the lamina

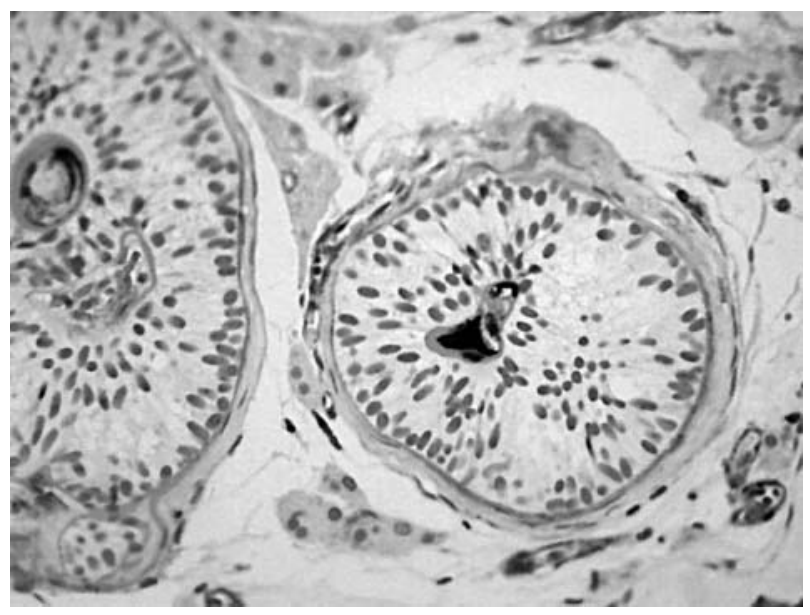

Figure 3 The thickened basement membrane material was immunoreactive for collagen type IV. Staining for type IV collagen was linear and present in the basement membrane close to the basal regions of the Sertoli cells. In addition, the rounded hyaline cores also showed immunoreactivity for collagen type IV (immunohistochemistry with antitype IV collagen). 


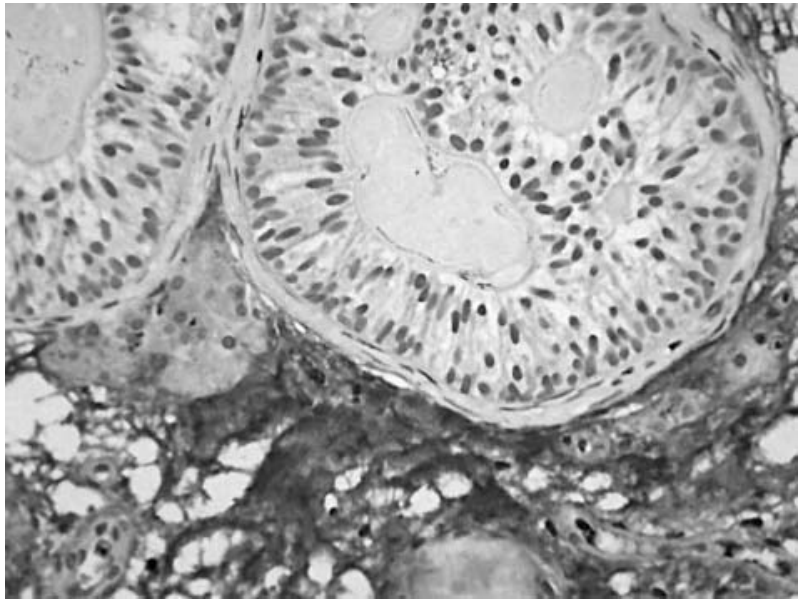

Figure 4 The surrounding interstitium stained with anti-fibronectin but the hyaline deposits and cores were negative (immunohistochemistry with anti-fibronectin).

propria by the basement membrane. The basement membrane is an acellular, amorphous layer of extracellular matrix and is normally 0.1 to $0.2 \mu \mathrm{m}$ thick. ${ }^{4}$ In conditions producing alterations in spermatogenesis, the lamina propria, inclusive of the basement membrane, shows a considerable increase in thickness. This thickening is predominantly attributed to an increase in the extracellular matrix between the cellular layers. Although these cellular layers remain constant in volume and number regardless of the variation in thickness, the inner layers of myofibroblasts lose their myoid qualities and are transformed into fibroblasts. ${ }^{5}$ The newly formed fibroblasts also participate in secretion of extracellular matrix components, further contributing to the increased thickness of the lamina propria. In our series, thickening of the basement membrane was a consistent finding in all 46 cases.

Ultrastructurally, the basement membrane consists of three layers. The lamina lucida close to the Sertoli cells, the lamina densa (basal lamina), and the lamina reticularis, a discontinuous layer containing fibrous elements. ${ }^{6}$ It has been shown that type IV collagen, laminin, fibronectin, and heparan sulfate proteoglycan are localised to the basal lamina part of the basement membrane. ${ }^{7}$ Because both laminin and fibronectin bind with type IV collagen and heparan sulfate, it has been suggested that these four components form an integrated complex, which constitutes the basal lamina. ${ }^{7}$

Recent immunohistochemical studies of rat seminiferous tubules showed that the basement membrane immediately adjacent to the seminiferous epithelium is composed of type IV collagen, laminin, heparan sulfate, and entactin. Fibronectin was localised to the connective tissue external to the myoid cells and did not constitute part of the inner acellular basement membrane. ${ }^{4}$ These findings are in agreement with our present results, which confirmed type IV collagen positivity and fibronectin negativity in the hyaline material within the Sertoli cell nodules, strongly suggesting that this material is of basement membrane origin.

The distribution of laminin, fibronectin, and type IV collagen in normal and cryptorchid testes has been documented. ${ }^{8}$ Fibronectin is present throughout the thickness of the lamina propria. It has been shown that there is no difference in the distribution of fibronectin in the normal and cryptorchid testis. Laminin is present in the innermost part of the lamina propria and its distribution in normal and cryptorchid prepubertal testes is the same. However, in adult

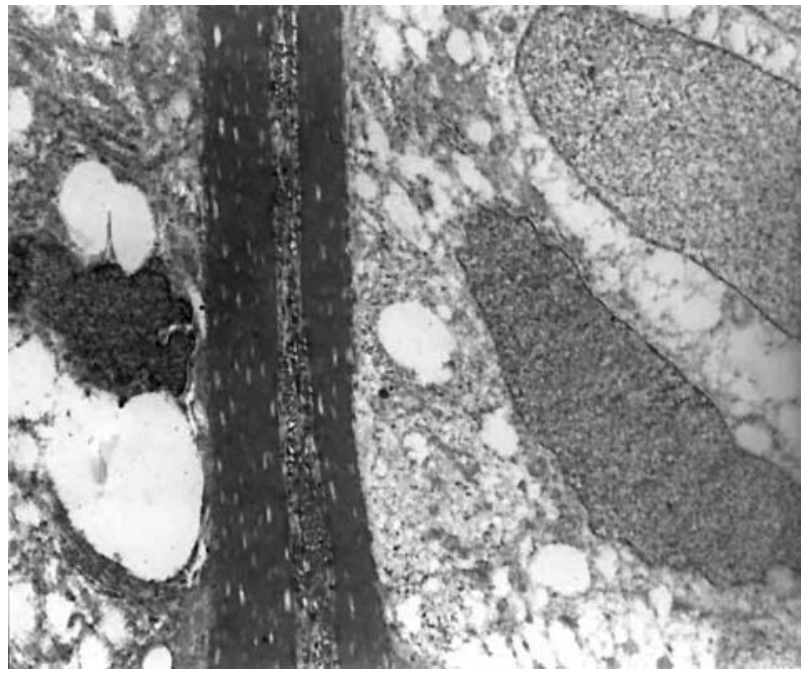

Figure 5 Thickened multilamellar basement membranes with intervening interstitium (original magnification, $\times 5000$ ).

cryptorchid testes laminin deposits formed numerous deep invaginations into the seminiferous epithelium. These invaginations have been ascribed to infoldings of the basal lamina and are not the result of a primary alteration of laminin deposition. Type IV collagen is present throughout the lamina propria of normal testes, but there is a deficiency of type IV collagen in cryptorchid testes. The deficiency is attributed to a primary, congenital deficiency of the cryptorchid testis (that is, intrinsic factors), rather than to hormonal alterations, increased abdominal temperature, or autoimmune responses (that is, extrinsic factors).

"Our present results confirmed type IV collagen positivity and fibronectin negativity in the hyaline material within the Sertoli cell nodules, strongly suggesting that this material is of basement membrane origin"

Sertoli cells are the only non-germinal components of the seminiferous tubule and have an important secretory function, producing seminiferous tubule fluid and several

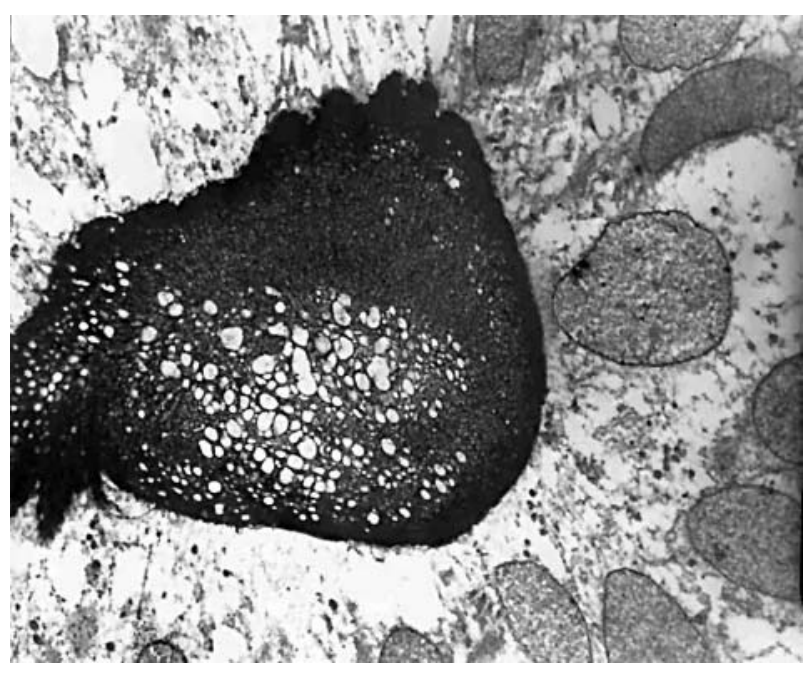

Figure 6 Hyaline core showing similar lamellated basement membrane material (original magnification, $\times 1500$ ). 
peptides, proteins, and steroids. ${ }^{9}$ Seminiferous tubule fluid is essential for the nutrition of the germ cells and released sperm. It has a presumed role in the transport of chemical substances from the basal to apical seminiferous tubule, thus facilitating cell to cell communication between Sertoli cells and germ cells.

Up to 100 peptides and proteins are also secreted, including extracellular matrix components, such as type IV collagen, laminin, and both chondroitin and keratan sulfates. However, fibronectin secretion has not been demonstrated and, along with type IV collagen and chondroitin sulfate, fibronectin is produced by the myoid cells of the lamina propria. ${ }^{10}$ Type IV collagenase and other metalloproteinases are responsible for remodelling of the basement membrane and seminiferous tubule.

In a study of testicular biopsies from infertile men showing Sertoli cell only tubules, four morphological types of Sertoli cells were identified: mature, immature, dysgenetic, and involuting. The differing Sertoli cell types are probably related to the different aetiological factors that determine the common testicular pattern of Sertoli cell only tubules. ${ }^{11}$ Cryptorchid testes showed dysgenetic and occasional normal Sertoli cells.

Sertoli cells are mitotically active mainly in the sexually immature testis, whereas their numbers in adult mammals remain stable. ${ }^{12}$ It is possible that Sertoli cells are mitotically active in the cryptorchid testis, which is sexually immaturehence, the occurrence of Sertoli cell proliferation in this setting. Alternatively, Sertoli cell proliferation might be interpreted as the result of developmental arrest of the seminiferous tubule. The lack of lengthening of the seminiferous tubule prevents the widespread distribution of Sertoli cells. ${ }^{1}$

Several factors have been suggested to explain the presence of immature Sertoli cells in cryptorchid testes. These include the increased temperature of the undescended testis, associated congenital lesions, and hormonal influences. ${ }^{1}$

Sertoli cell nodules must be differentiated from the recently described intratubular Sertoli cell proliferations. Although both lesions contain architectural patterns reminiscent of SCTAT, cytologically the proliferative Sertoli cells in intratubular Sertoli cell proliferations are larger, with ovoid euchromatic nuclei, often multiple nucleoli, and eosinophilic cytoplasm, whereas Sertoli cell nodules contain infantile Sertoli cells with scant amounts of cytoplasm. In addition, a strong association exists between intratubular Sertoli cell proliferations and the Puetz-Jeghers syndrome. ${ }^{2}$ Whether intratubular Sertoli cell proliferations represent a non-neoplastic, proliferative phenomenon or an intraepithelial stage in the evolution of certain Sertoli cell tumours is still controversial. ${ }^{2}$ Although the first option is favoured, it is possible that some intratubular Sertoli cell proliferations can grow beyond the confines of the seminiferous tubule and develop into Sertoli cell tumours, most commonly, large cell calcifying Sertoli cell tumours. Careful follow up is required in these cases and orchidectomy is indicated if a testicular mass appears. Sertoli cell nodules described in cryptorchid testes do not appear to pose such a threat. Similarly, Sertoli cell nodules should be distinguished from Sertoli cell tumours.

Hyperplasia of Sertoli cells has been described in cryptorchid testes, ${ }^{1}$ but we have described a lesion conforming to a nodular form of Sertoli cell hyperplasia with prominent basement membrane deposition. The staining reactions are consistent with the presence of both matrix and fibrous components of basement membranes. Furthermore, the ultrastructural components of the hyaline material are similar to that of the basement membrane of seminiferous tubules. Is there an increased production of basement
Take home messages

- We have described an unusual form of Sertoli cell proliferation in undescended testes, which must be distinguished from Sertoli cell tumours and other forms of proliferation that have an increased incidence of testicular tumours

- The hyaline material within Sertoli cell nodules in the cryptorchid testis is histochemically, immunohistochemically, and ultrastructurally consistent with both matrix and fibrous components of seminiferous tubule basement membranes

- Thus, increased production of basement membrane material, with subsequent invagination into tubules, is the most likely origin of this material

- The histochemical and immunohistochemical reactivity of hyaline deposits in Sertoli cell nodules and sex cord tumour with annular tubules are identical, supporting the view that this tumour shows Sertoli cell differentiation

membrane material with subsequent invagination into the tubules in an "intratubular" growth pattern?

In conclusion, our study has described an unusual form of Sertoli cell proliferation in the clinical context of undescended testes. These nodules must be distinguished from Sertoli cell tumours and other forms of proliferation in this specific context in which there is an increased incidence of testicular tumours. At this stage, there is no evidence to suggest that these nodules are preneoplastic. Furthermore, our study has revealed that the histochemical and immunohistochemical reactivity of hyaline deposits in Sertoli cell nodules and SCTAT are identical. This is supportive of the view that SCTAT shows Sertoli cell differentiation. ${ }^{13}{ }^{14}$

\section{ACKNOWLEDGEMENTS}

The authors thank Dr M Duffield for reviewing the electron microscopy.

\section{Authors' affiliations}

D Govender, Y Sing, R Chetty, Department of Pathology, Nelson R

Mandela School of Medicine, University of Natal, Private Bag 7,

Congella, Durban, 4013, South Africa

\section{REFERENCES}

1 Nistal M, Paniagua R, Abaurrea MA, et al. Hyperplasia and the immature appearance of Sertoli cells in primary testicular disorders. Hum Pathol 1982;13:3-12

2 Venara M, Rey R, Bergadá I, et al. Sertoli cell proliferations of the infantile testis: an intratubular form of Sertoli cell tumor? Am J Surg Pathol 2001;25:1237-44.

3 DeKretser DM, Kerr JB, Paulsen CA. The peritubular tissue in the normal and pathological human testis. An ultrastructural study. Biol Reprod 1975; 12:317-24.

4 Dym M. Basement membrane regulation of Sertoli cells. Endocr Rev 1994;15:102-15.

5 Davidoff MS, Breucker $\mathrm{H}$, Holstein AF, et al. Cellular architecture of the lamina propria of human seminiferous tubules. Cell Tissue Res 1990;262:253-61.

6 Laurie GW, Leblond CP. What is known of the production of basement membrane components? J Histochem Cytochem 1983:31:159-63.

7 Laurie GW, Leblond CP, Martin GR. Localization of type IV collagen, laminin, heparan sulfate proteoglycan, and fibronectin to the basal lamina of basement membranes. J Cell Biol 1982;95:340-4.

8 Santamaria L, Martinez-Onsurbe P, Paniagua R, et al. Laminin, type IV collagen, and fibronectin in normal and cryptorchid human testes. An immunohistochemical study. Int J Androl 1990;13:135-46.

9 Jégou B. The Sertoli cell. Baillieres Clin Endocrinol Metab 1992;6:273-311. 
10 Tung PS, Fritz IB. Morphogenetic restructuring and formation of basement membranes by Sertoli cells and testis peritubular cells in co-culture: inhibition of the morphogenetic cascade by cyclic-AMP derivatives and blocking direct cell contact. Dev Biol 1987;120:139-53.

11 Nistal M, Jimenez F, Paniagua R. Sertoli cell types in the Sertoli-cell-only syndrome: relationships between Sertoli cell morphology and aetiology. Histopathology 1990;16:173-80.
12 Clermont Y. Perey B. Quantitative study of the cell population of the seminiferous tubules in immature rats. Am J Anat 1957;100: 241-66.

13 Tavassoli FA, Norris HJ. Sertoli tumours of the ovary. Cancer 1980:46:2281-97.

14 Young RH, Scully RE. Ovarian sex cord-stromal tumors: recent advances and current status. Clin Obstet Gynecol 1984;11:93-134.

\section{Clinical Evidence-Call for contributors}

Clinical Evidence is a regularly updated evidence based journal available worldwide both as a paper version and on the internet. Clinical Evidence needs to recruit a number of new contributors. Contributors are health care professionals or epidemiologists with experience in evidence based medicine and the ability to write in a concise and structured way.

\section{Currently, we are interested in finding contributors with an interest in} the following clinical areas:

Altitude sickness; Autism; Basal cell carcinoma; Breast feeding; Carbon monoxide poisoning; Cervical cancer; Cystic fibrosis; Ectopic pregnancy; Grief/bereavement; Halitosis; Hodgkins disease; Infectious mononucleosis (glandular fever); Kidney stones; Malignant melanoma (metastatic); Mesothelioma; Myeloma; Ovarian cyst; Pancreatitis (acute); Pancreatitis (chronic); Polymyalgia rheumatica; Post-partum haemorrhage; Pulmonary embolism; Recurrent miscarriage; Repetitive strain injury; Scoliosis; Seasonal affective disorder; Squint; Systemic lupus erythematosus; Testicular cancer; Varicocele; Viral meningitis; Vitiligo However, we are always looking for others, so do not let this list discourage you.

Being a contributor involves:

- Appraising the results of literature searches (performed by our Information Specialists) to identify high quality evidence for inclusion in the journal.

- Writing to a highly structured template (about 2000-3000 words), using evidence from selected studies, within 6-8 weeks of receiving the literature search results.

- Working with Clinical Evidence Editors to ensure that the text meets rigorous epidemiological and style standards.

- Updating the text every eight months to incorporate new evidence.

- Expanding the topic to include new questions once every 12-18 months.

If you would like to become a contributor for Clinical Evidence or require more information about what this involves please send your contact details and a copy of your CV, clearly stating the clinical area you are interested in, to Claire Folkes (cfolkes@bmigroup.com).

\section{Call for peer reviewers}

Clinical Evidence also needs to recruit a number of new peer reviewers specifically with an interest in the clinical areas stated above, and also others related to general practice. Peer reviewers are health care professionals or epidemiologists with experience in evidence based medicine. As a peer reviewer you would be asked for your views on the clinical relevance, validity, and accessibility of specific topics within the journal, and their usefulness to the intended audience (international generalists and health care professionals, possibly with limited statistical knowledge). Topics are usually 2000-3000 words in length and we would ask you to review between 2-5 topics per year. The peer review process takes place throughout the year, and our turnaround time for each review is ideally 10-14 days.

If you are interested in becoming a peer reviewer for Clinical Evidence, please complete the peer review questionnaire at www.clinicalevidence.com or contact Claire Folkes(cfolkes@bmjgroup.com). 